\title{
Gastrointestinal Lymphoma in Southwest China: Subtype Distribution of 1,010 Cases Using the WHO (2008) Classification in a Single Institution
}

\author{
Wenshuang Ding Sha Zhao Jianchao Wang Qunpei Yang Hong Sun \\ Jiaqi Yan Limin Gao Wenqing Yao Wenyan Zhang Weiping Liu \\ Department of Pathology, West China Hospital of Sichuan University, Chengdu, PR China
}

\section{Key Words}

Diffuse large B cell lymphoma - Extra-nodal NK/T cell lymphoma nasal type · Gastrointestinal tract $\cdot$ Non-Hodgkin lymphoma $\cdot$ WHO classification

\begin{abstract}
The gastrointestinal tract (GIT) is the most common anatomic site of extranodal non-Hodgkin lymphoma (NHL) involvement. The classification criteria of lymphoma have changed in recent decades, and few large-sample studies regarding subtype analysis of lymphoma have been performed in this site. Aim: Therefore, the present study was conducted to analyze the histological subtype distribution of the GIT. Method: All patients in a single institution with a diagnosis of primary NHL in the GIT were enrolled between January 2007 and April 2014. The patients were categorized according to the WHO (2008) classification of tumors of hematopoietic and lymphoid tissue. Result: A total of 1,010 eligible cases diagnosed as $\mathrm{NHL}$ were collected in this study. The male:female ratio was $1.7: 1$ and the median age was 55 years. The percent of patients with lymphoma involvement in the stomach was $52 \%(n=522)$, and the remaining $48 \%$ $(n=484)$ had intestinal tract involvement. Histologically, diffuse large $B$ cell lymphoma (DLBCL) was the most common
\end{abstract}

subtype in all of the GIT lymphoma cases, and was also the most common subtype in cases involving the stomach (78\%) and the intestinal tract (53\%). The incidence of DLBCL and mucosa-associated lymphoid tissue lymphoma in the stomach was significantly higher than the incident in the intestinal tract $(p<0.01)$. T and NK cell lymphoma was significantly more common in the intestinal tract than in the stomach $(p<0.01)$. Extranodal NK/T cell lymphoma nasal type (ENKTL$\mathrm{N})$ was the most common subtype of T and NK cell lineage lymphoma in GIT and was also the second most common intestinal tract-involved lymphoma. Conclusion: DLBCL was the most frequent lymphoma in the stomach and in the intestinal tract. T and NK cell lineage lymphoma had a higher occurrence in the intestinal tract than in the stomach. ENKTL-N was the most frequent subtype of lymphoma derived from NK/T cell lineage, and was the second most common lymphoma among all intestinal tract lymphomas.

(c) 2015 S. Karger AG, Basel

\section{Introduction}

Lymphoid neoplasms are diverse malignant entities in terms of different cell lineages and clinical courses, as well as varying degrees of treatment response and prognosis

\section{KARGER}

E-Mail karger@karger.com

www.karger.com/aha
(C) 2015 S. Karger AG, Basel

$0001-5792 / 15 / 1351-0021 \$ 39.50 / 0$
Wenyan Zhang, MD or Weiping Liu, MD

Department of Pathology, West China Hospital of Sichuan University 37 Guoxue Xiang Street

Wuhou District, Chengdu 610041 (PR China)

E-Mail zhangwyliu@ hotmail.com or liuweiping2001@vip.sina.com 
outcome. Different cell lineages and different subtypes of lymphoma have displayed reverse incidence trends over the past 2 decades [1-3]. With further understanding of this malignancy, recategorization of lymphoid neoplasms from the Revised European-American Lymphoma (REAL) classification to the World Health Organization (WHO) classification and its updated versions was challenging $[4,5]$. Immunophenotype, genetic alterations and some known risk factors of etiology have also been studied and included in the definition of each lymphoma subtype in the new version of the WHO classification criteria.

Lymphoid neoplasms can be classified into Hodgkin lymphoma and Non-Hodgkin lymphoma (NHL). Nearly all cases of Hodgkin lymphoma involve nodal lesions. NHL can be diagnosed as a nodal or extranodal lymphoma. Extranodal lymphoma refers to a lymphoma arising primarily from a site other than a lymph node, the spleen, bone marrow or mediastinum (lymph node and thymus). The gastrointestinal tract (GIT) is one of the most common anatomic sites of extranodal lymphoma involvement, accounting for 6-23\% of all NHLs [6-9] and $0.9-6.5 \%$ of all gastrointestinal malignances $[10,11]$. Accumulating studies focusing on the subtype distribution of lymphoma in the GIT have been conducted globally, each demonstrating noteworthy and diverse characteristics due to geographic diversity, different ethnic groups and environmental elements, among other factors [1214].

To our knowledge, no epidemiological research on the distribution of subtypes of NHL in the GIT, according to the updated version of the WHO classification criteria (2008), have been conducted in China involving a large sample of patients. Moreover, the majority of previous related studies were conducted according to various histological classification criteria, which made a comparison among studies difficult. This retrospective study was performed to analyze the distribution of subtypes of NHL in the GIT, and to offer new insight for future studies of pathogenesis in this anatomic site.

\section{Patients and Methods}

Patients with gastrointestinal lymphoma were identified from the computerized database of all patient cases in the Department of Pathology, West China Hospital of Sichuan University. Primary gastrointestinal lymphoma was defined as cases presenting with gastrointestinal symptoms or a tumor located in the GIT [15]. The cases that had a previous history of lymphoma that later recurred in the GIT were defined as secondary. Repeated biopsies from a single case and lymphoma cases from posttransplant patients were excluded. Cases with an uncertain diagnosis or an unclassified subtype of lymphoma in this site were also excluded from the present study. The diagnosis for each specimen was accomplished by an experienced pathologist who specialized in the lymphatic and hematopoietic system. From January 2007 to April 2014, a total of 1,010 cases were definitively diagnosed with NHL involving the GIT. Clinical information including demographics (age, gender) and initial anatomic site was collected from the pathological samples and application forms for consultation. The study protocol was approved by the Ethics Committee of West China Hospital of Sichuan University.

The non-Hodgkin diagnosis was confirmed by hematoxylin eosin staining (HE) and inmmunohistochemistry staining. For the latter, a panel of antibodies were used to aid in the diagnosis or differential diagnosis as follows: CD3, CD $3 \varepsilon, \mathrm{CD} 4, \mathrm{CD} 5, \mathrm{CD} 8, \mathrm{CD} 10$, CD15, CD20, CD21, CD23, CD30, CD43, CD45RO, CD 56, CD79 $\alpha$, CD99, ALK-1, EMA, cyclin D1, BCL-2, BCL-6, Mum-1, $\kappa$ and $\lambda$ light chain, granzyme B, TIA-1, TDT and Ki-67. In situ hybridization for Epstein-Barr virus (EBV)-encoded small RNA (EBER) and $\mathrm{IgH}$ and/or TCR gene rearrangement was also conducted when necessary. The subtype classification was carried out according to the WHO classification of tumors of hematopoietic and lymphoid tissues (2008).

\section{Statistical Analysis}

Statistical analysis was performed using SPSS version 17.0. The comparison of lymphoma incidence among different cell lineages and the frequency of the lymphoma subtypes that involved the stomach and intestinal tract were calculated using the $\chi^{2}$ test method. Statistical significance was assigned at the $5 \%$ level $(\mathrm{p}<0.05)$.

\section{Results}

A total of 1,010 patients diagnosed with NHL in the GIT were enrolled between January 2007 and April 2014. In this study, there were 451 consultant cases (44.7\%), and the remaining 559 cases $(55.3 \%)$ were inpatients. The average age and sex distribution are provided in table 1. The entire sample was composed of 638 males and 372 females, with a male:female ratio of 1.7:1. The median age was 55 years, with a range of $2-88$ years.

The incidence of lymphoma and various histological subtypes along the anatomic sites are shown in figure 1. In total, 522 cases (52\%) involved the stomach, and the remaining 484 cases (48\%) involved the intestinal tract. Regarding histological subtype classification, lymphoma derived from a B cell lineage accounted for $87 \%(n=880)$, and lymphomas originating from NK/T cells accounted for $13 \%(n=130)$. In the group of B cell lineage lymphomas, diffuse large B cell lymphoma (DLBCL) was the most frequent subtype, followed by mucosa-associated lymphoid tissue (MALT) lymphoma, mantle cell lymphoma (MCL) and Burkitt lymphoma (BKL), in decreas- 


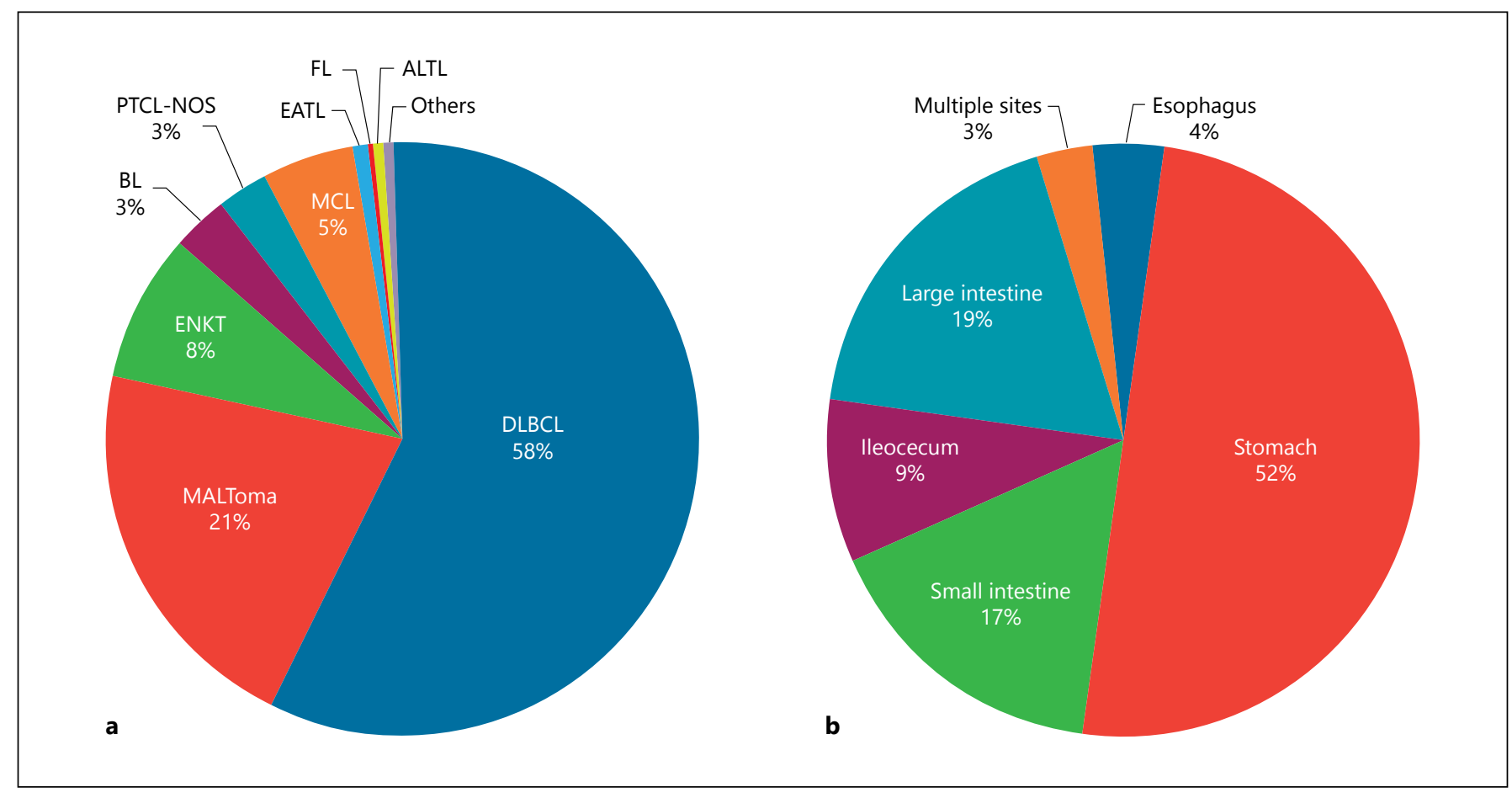

Fig. 1. a The distribution of NHL in GIT; 'others' include 3 cases of lymphoblastic lymphoma and 1 case of extramedullary plasmacytoma. $\mathbf{b}$ The involved anatomic sites along the GIT.

ing order. The remaining cases were diagnosed as follicular lymphoma (FL, $\mathrm{n}=3)$, lymphoblastic lymphoma $(\mathrm{n}=$ 3 ) and extramedullary plasmacytoma $(n=1)$. Moreover, in 406 cases in the DLBCL group, immunohistochemistry staining of CD10, BCL- 6 and MUM-1 was conducted according to Hans' classification. The results implied that 159 cases were germinal center B cell-like (GCB) subtype and the remaining 247 cases were non-GCB subtype. For MALT lymphoma, the majority of cases presented an indolent characteristic represented by a low $\mathrm{Ki}-67$ index, while 9 cases showed partial DLBCL translation. In the group of NK/T cell-derived lymphoma, extranodal NK/T cell lymphoma nasal type (ENKTL-N) was the most common histological subtype, accounting for $8.3 \%$ of all NHL. EBV in situ hybridization (EBER) was performed on 77 of the 84 ENKTL-N cases, and 91\% (70/77) were positive. The other $\mathrm{T}$ cell-originating lymphoma cases included peripheral $\mathrm{T}$ cell lymphoma not otherwise specified (PTCL-NOS; 2.6\%), enteropathy-associated T cell lymphoma (EATL; 1.1\%) and anaplastic large cell lymphoma (ALCL; 0.9\%), in order of decreasing frequency.

The comparison of lymphoma subtypes between the stomach and intestinal tract is detailed in table 2. The most common anatomic site of GIT lymphoma was the
Table 1. Study demographics

\begin{tabular}{|c|c|c|c|}
\hline & $\begin{array}{l}\text { Male:female } \\
\text { ratio }\end{array}$ & $\begin{array}{l}\text { Mean } \\
\text { age, years }\end{array}$ & $\mathrm{n}$ \\
\hline Male & & & 638 \\
\hline Female & & & 372 \\
\hline Median age, years & & & $55(2-88)$ \\
\hline \multicolumn{4}{|l|}{ Lymphoma subtype } \\
\hline DLBCL & $1.4: 1$ & 55 & $580(57.4)$ \\
\hline MALT lymphoma & $1.5: 1$ & 58 & $209(20.7)$ \\
\hline MCL & $5.3: 1$ & 61 & $50(5.0)$ \\
\hline $\mathrm{BL}$ & $3.9: 1$ & 23 & $34(3.4)$ \\
\hline $\mathrm{FL}$ & $0: 3$ & 45 & $3(0.3)$ \\
\hline Other B cell lymphoma & $1: 1$ & & $4(0.4)$ \\
\hline ENKTL-N & $3.7: 1$ & 39 & $84(8.3)$ \\
\hline PTCL-NOS & $3.3: 1$ & 51 & $26(2.6)$ \\
\hline EATL & 10:1 & 61 & $11(1.1)$ \\
\hline ALCL & $2: 1$ & 49 & $9(0.9)$ \\
\hline \multicolumn{4}{|l|}{ Site along the GIT } \\
\hline Esophagus & $3: 1$ & 51 & $4(0.4)$ \\
\hline Stomach & $1.3: 1$ & 56 & $521(51.6)$ \\
\hline Small intestine & $2.6: 1$ & 51 & $173(17.1)$ \\
\hline Ileocecum & $1.8: 1$ & 48 & $92(9.1)$ \\
\hline Large intestine & $2.2: 1$ & 49 & $186(18.4)$ \\
\hline Multiple sites & $5.8: 1$ & 52 & $34(3.4)$ \\
\hline
\end{tabular}

Values in parentheses are either the range or percentage. 
Table 2. Distribution of NHL along the GIT

\begin{tabular}{|c|c|c|c|c|c|c|c|c|c|c|c|}
\hline Anatomic site & \multicolumn{6}{|c|}{ B cell lymphoma, $\mathrm{n}$} & \multicolumn{4}{|c|}{ T cell lymphoma, $\mathrm{n}$} & Total, n \\
\hline Stomach & 327 & 157 & 8 & 6 & 1 & 2 & 5 & 8 & 6 & 2 & 522 \\
\hline Small intestine & 87 & 26 & 12 & 10 & 0 & 2 & 17 & 10 & 2 & 6 & 172 \\
\hline Ileocecum & 64 & 6 & 6 & 2 & 0 & 0 & 14 & 0 & 0 & 0 & 92 \\
\hline Total & 580 & 209 & 34 & 50 & 3 & 4 & 84 & 26 & 9 & 11 & 1,010 \\
\hline
\end{tabular}

stomach (52\%), followed by the large intestine (19\%), small intestine (17\%), ileocecum (9\%) and multiple involved sites (3\%). There were 4 cases of esophagus involvement ( 2 cases of DLBCL, 1 case of MALT lymphoma and 1 case of ENKTL). In the stomach, DLBCL was the most common histological subtype (78\%) followed by MALT lymphoma (14\%), both of which accounted for $92 \%$ of all lymphomas of the stomach. The other subtypes of B cell lymphoma $(\mathrm{BKL}=8, \mathrm{MCL}=6, \mathrm{FL}=1$, B lymphoblastic lymphoma $=2$ ) and $\mathrm{T}$ and $\mathrm{NK}$ cell lymphoma $(\mathrm{ENKTL}=5, \mathrm{PTCL}-\mathrm{NOS}=8, \mathrm{ALCL}=6, \mathrm{EATL}=2)$ constituted the other $8 \%$ of stomach-involved lymphomas. Statistically, the incidence of DLBCL and MALT lympho$\mathrm{ma}$ in the stomach was higher than that of intestinal tract $(\mathrm{p}<0.01)$. In the intestinal tract, the distribution of histological subtypes was more complex than that observed in the stomach. DLBCL was the most common intestinal lymphoma (53\%). Strikingly, the second most common subtype in the intestinal tract was ENKTL-N (16\%), which originated from $T$ and NK cell lineage. MALT lymphoma accounted for $11 \%$ of cases involving the intestinal tract, making it the third most common. T and NK cell-originating lymphoma in the intestinal tract, including ENKTL-N, PTCL-NOS and EATL, displayed a significantly higher frequency compared to those in the stomach $(\mathrm{p}<0.01)$. Moreover, a significantly higher frequency of intestinal tract involvement also existed in $\mathrm{BKL}$ and MCL compared with that in the stomach $(\mathrm{p}<0.01)$.

The age and sex distribution by histological subtype is shown in figure 2. Overall, the incidence of GIT lymphoma increased with age and reached its peak in patients who were 51-60 years old. The median age of each histological subtype is shown in table 1. DLBCL and MALT lymphoma shared the same peak age group, which was between 51 and 60 years. For ENKTL-N, the highest peak of incidence oc- curred in patients aged $31-40$ years, with a mean age of 39 years. However, the highest peak of incidence for MCL was in patients aged between 61 and 70 years. BKL was predominant in pediatric patients, and its highest peak of incidence was in patients aged under 10 years. For each subtype of NHL in this study, there were more male patients than females.

\section{Discussion}

Currently, this epidemiological study is the largest comprehensive descriptive research on the subtype distribution of gastrointestinal lymphoma according to the 2008 WHO classification of tumors of hematopoietic and lymphoid tissues conducted in a single institution. Of the 1,010 enrolled cases, 451 (45\%) individuals were consulted patients who came from the districts of Sichuan province, which, to an extent, represents the present conditions of Southwest China.

GIT NHL represents a heterogeneous group of diseases that are characterized by different sites of involvement, histological subtypes and treatment outcomes. The GIT is the most common anatomic site of extranodal lymphoma involvement. Considering geographic diversity, various ethnic backgrounds and environmental exposures, the epidemiology is globally diverse. In the current study, the median overall age of GIT-NHL was 55 years. For gender distribution, the incidence of GIT-NHL in males was higher than in females, with a ratio of 1.7:1. A series of related studies were compared and are listed in table 3. For example, a study including 216 cases of GIT lymphoma was performed by Li et al. [16] in GuangZhou, a city of Southeast China, showing that the median age was 50 years and the gender ratio was 2.9:1. In a study by Ding et 


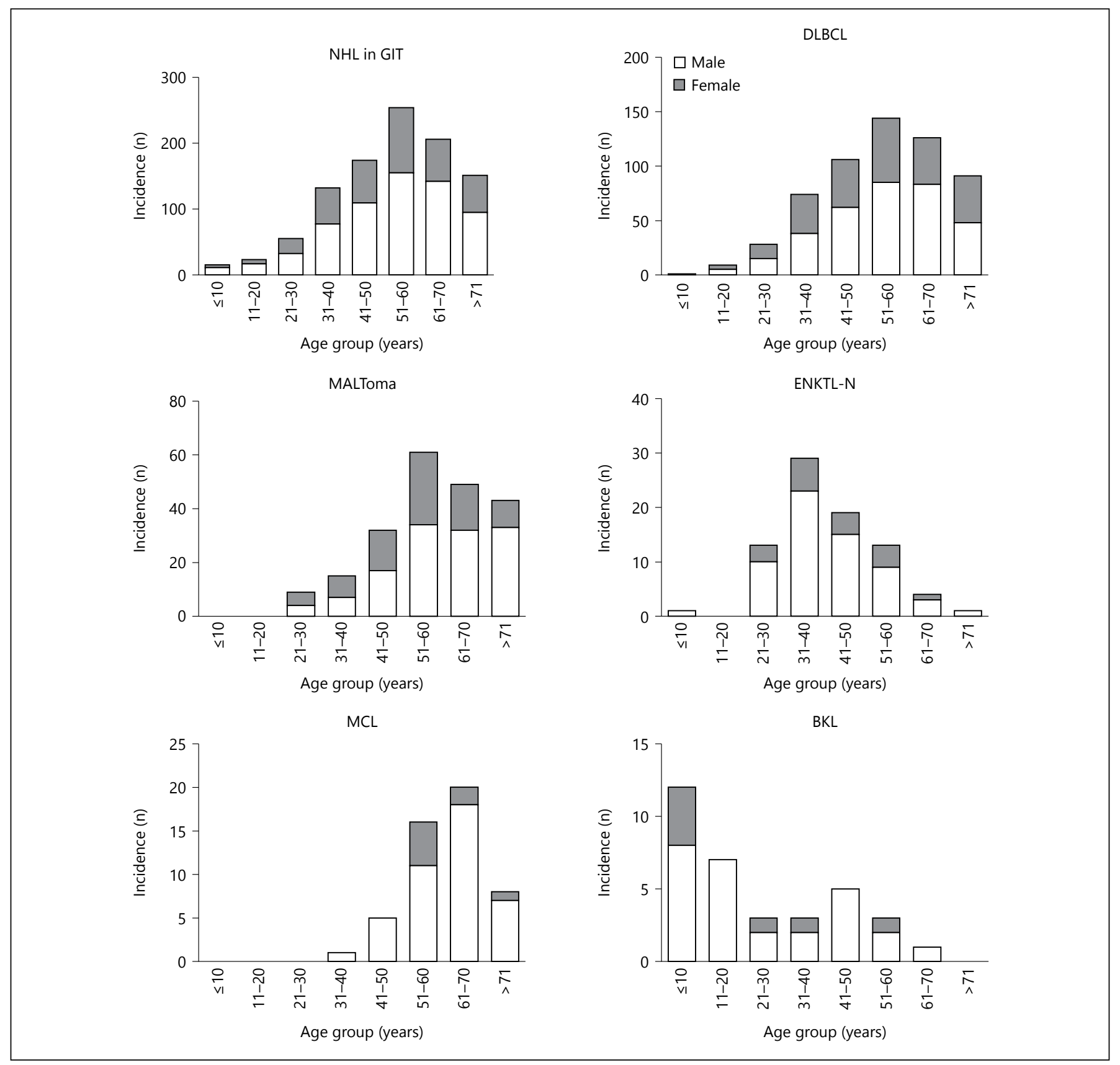

Fig. 2. Age and sex distribution in all histological subtypes.

al. [17], 46 cases of GIT lymphoma were analyzed in DaLian, a city located in Northeast China. The results indicated that the average age was 50 years and the gender ratio was 1.3:1. Compared with studies conducted in other countries, differences of the same items were the most marked. In India, a study was conducted by Arora et al. [18] using 336 cases of GIT lymphoma, which indicated that the mean age was 45 years and the gender ratio was 3.93:1. Regarding North American countries, 2 related studies were performed in the USA and Canada, using 216 and 149 cases, respectively. The results showed that the average age was 61 and 63.8 years, and that the gender ratio was $1.7: 1$ and $1.5: 1$, respectively $[3,18,19]$. The gender ratio of this study was similar to that of North 
Table 3. GIT lymphoma: comparison with the literature

\begin{tabular}{|c|c|c|c|c|c|c|c|c|}
\hline First author & Country & Cases, $\mathrm{n}$ & $\begin{array}{l}\text { Male/female } \\
\text { (ratio) }\end{array}$ & $\begin{array}{l}\text { Average } \\
\text { age (range), } \\
\text { years }\end{array}$ & \multicolumn{3}{|c|}{ Anatomic sites, $\mathrm{n}$} & $\begin{array}{l}\text { Period of } \\
\text { study }\end{array}$ \\
\hline Ding [17] & China & 46 & $26 / 20(1.3: 1)$ & $50(21-81)^{\mathrm{b}}$ & 24 & 22 & 0 & 1998-2012 \\
\hline Arora [18] & Indian & 336 & $267 / 68(3.9: 1)$ & $45(3-88)^{b}$ & 180 & 147 & 9 & $2001-2010$ \\
\hline Howell [3] & Canada & 149 & $89 / 60(1.5: 1)$ & $63.8(22-90)^{\mathrm{b}}$ & 70 & 65 & 13 & 1999-2009 \\
\hline
\end{tabular}

$\mathrm{S}=$ Stomach $\mathrm{I}=$ intestinal tract $; \mathrm{M}=$ multiple sites.

${ }^{\mathrm{a}}$ Median value. ${ }^{\mathrm{b}}$ Mean value.

American countries and lower than that in India. However, because some research was only conducted in adults, the comparison of average age is meaningless.

The stomach is the main site of GIT involvement with a frequency reported to be between 38.5 and $75 \%$ $[3,12,14,16,18-20]$. In our series, the frequency was $52 \%$. The frequencies of involvement with other anatomic sites were $19 \%$ for the large intestine, $17 \%$ for the small intestine, $9 \%$ for the ileocecum, $3 \%$ for multiple sites and esophagus with a frequency of less than $1 \%$. According to previous studies, the second most common anatomic site of GIT lymphoma is diverse. For instance, the small intestine was the second most commonly affected site in the research of Warrick et al. [19]. The ileocecum region was defined as the section from the terminal of the ileum to the cecum, because of the ambiguity of anatomic classification, the designation for this region was different among previous studies, which has caused the different frequencies of affected small intestinal lymphoma and large intestinal lymphoma $[3,18,19]$. Thus, in the current study, we isolated this section as an independent area, belonging to neither the small nor the large intestine. This contributed to the difference in the second most frequently involved site compared with other studies. Furthermore, in this study, there were 4 cases of NHL that involved the esophagus with the following subtypes: 2 cases of DLBCL, 1 case of MALT lymphoma and 1 case of ENKTL. The esophagus is a rarely involved site and it is seldom that primary lymphoma originates from this section. Esophageal involvement usually results from metastasis from cervical or mediastinal lymph nodes or extension from gastric lymphoma $[6,11]$.

In this study, the incidence of $\mathrm{T}$ and $\mathrm{NK}$ cell lineage lymphoma was relatively high, with a proportion of $13 \%$.
Other researchers have previously reported a rate of 3.7$9 \%[3,12,14,18]$. In terms of histological distribution, DLBCL was the most common lymphoma followed by MALT lymphoma, with a proportion of 50.4 and $20.7 \%$, respectively. This result was consistent with the results of other worldwide studies. However, it differs from the study by Yoon et al. [1], in which MALT lymphoma was the most common subtype and DLBCL was the second most common subtype (MALT lymphoma $43.2 \%$ vs. DLBCL 42.2\%), geographic factors and ethnic origins may have contributed to the difference [1]. Immunohistochemical staining was conducted on 406 cases of DLBCL in this study using antibodies against CD10, BCL-6 and MUM-1. According to Hans' algorithm, the frequency of the non-GCB subtype was higher than that of the GCB subtype, which coincided with other studies [21]. A study conducted by Zhang et al. [22] indicated that the non-GCB subtype had a higher frequency of local lymph node involvement, which also implied a poor 5 -year overall survival compared with the GCB subtype. In our previous study, subtype distribution of all NHL in our institution indicated some differences when compared with the same items of GIT, which showed that DLBCL, ENKTL-N, MALToma (Marginal/MALT lymphoma) and FL were the most frequent types of lymphoma in a descending incidence order [8].

Regarding the histological distribution according to anatomic site, the subtype composition in the stomach and the intestines was apparently different. In the stomach, DLBCL and MALT lymphoma were the most common subtypes, accounting for $92 \%$ in gastric lymphoma, with the remaining lymphomas comprising only a minority, which was consistent with the report made by Huang et al. [23]. The subtype distribution in the intestine was more diverse. In addition to DLBCL, there was a 
striking feature in this section in that ENKTL-N was the most common subtype lymphoma derived from NK/T cell lymphoma, which was also the second most common lymphoma in the intestinal tract. In others studies, PTCLNOS was the most common subtype of NK/T cell lineage lymphoma in GIT [7, 23, 24]. ENKTL-N is an aggressive NHL with unique epidemiological, etiological and clinical features. Its prevalence is high in Asia and South America, while it is relatively low in North American and European countries [25-28]. Our previous work indicated that the southwest region of China had a relatively high morbidity of ENKTL-N, which ranked as the second most common lymphoma subtype of all NHL. Furthermore, the intestine was one of the most common extranasal sites of ENKTL-N involvement, with a relatively high frequency of metastasis and dismal follow-up outcomes. Although the pathogenesis remains unclear, EBV infection was thought to be a triggering risk factor of the tumor genesis $[8,29]$.

Although DLBCL was also the most common histological subtype in the intestinal tract in other studies, the second most common subtype varies from region to region. For example, MCL (22\%) and FL (21\%) comprised a considerable fraction in the North American population, whereas MALT lymphoma accounted for less in this section. MALT lymphoma has been closely associated with Helicobacter pylori infection; therefore, lower rates this infection and its earlier treatment may result in fewer MALT lymphoma diagnoses [19]. In India, BKL was the second most common subtype within the intestine [18]. With respect to the FL, MCL and BKL subtypes in this series, the fractions were relatively low at less than $9 \%$ for the three subtypes, and especially for FL, which was only $0.3 \%$.
As for gender-specific lymphoma, all of the subtypes showed a male predominance. The MCL and EATL subtypes displayed a striking male:female ratio of 5.3:1 and 10:1, respectively. A study of 30 cases of MCL by Ying et al. [30] revealed that the gender ratio was 3.3:1. However, the gender ratio of MCL located in the GIT was not mentioned in that report. In the Warrick et al. [19] study, 28 cases of GIT MCL were diagnosed with a gender ratio of 1:1. The striking predominance of GIT MCL cases among men requires verification through further research. Because of the limited specimens for EATL, the gender ratio of this subtype was unconvincing in this study and needs to be improved by expanding the number of samples. As for age-specific lymphoma, the occurrence of BKL was especially high in the younger aged patients, with a peak among the groups aged less than 10 years. ENKTL-N in the GIT reached the peak of morbidity at the age of 31-40 years. The average age of ENKTL-N in this study was 39 years. An ENKTL-N study composed of 81 cases of GIT involvement revealed that the average age was 45 years, which was older than the level of our study [31].

In summary, our large retrospective study from a single institution highlights the histological subtype and anatomic site distribution of cases of NHL in the GIT in the southwest region of China. DLBCL and marginal/ MALT lymphoma were significantly more frequent in the stomach than in the intestinal tract. The frequency of $\mathrm{T}$ and NK cell-derived lymphoma in the intestinal tract was higher than that in stomach. Strikingly, ENKTL-N was the most common subtype of T and NK cell lymphoma, and was also the second most common histological subtype of lymphoma that occurred in the intestinal tract.

\section{References}

1 Yoon SO, Suh C, Lee DH, Chi HS, Park CJ, Jang SS, Shin HR, Park BH, Huh J: Distribution of lymphoid neoplasms in the Republic of Korea: analysis of 5,318 cases according to the World Health Organization classification. Am J Hematol 2010;85:760-764.

2 Morton LM, Wang SS, Devesa SS, Hartge P, Weisenburger DD, Linet MS: Lymphoma incidence patterns by WHO subtype in the United States, 1992-2001. Blood 2006;107:265-276.

3 Howell JM, Auer-Grzesiak I, Zhang J, Andrews $\mathrm{CN}$, Stewart D, Urbanski SJ: Increasing incidence rates, distribution and histological characteristics of primary gastrointestinal nonHodgkin lymphoma in a North American population. Can J Gastroenterol 2012;26:452-456.
4 Harris NL, Jaffe ES, Stein H, Banks PM, Chan JK, Cleary ML, Delsol G, De Wolf-Peeters C, Falini B, Gatter KC, Grogan TM, Isaacson PG, Knowles DM, Mason DY, Muller-Hermelink H-K, Pileri SA, Piris MA, Ralfkiaer E, Warnke RA: A revised European-American classification of lymphoid neoplasms: a proposal from the International Lymphoma Study Group. Blood 1994;84:1361-1392.

5 Chan JKC, Quintanilla-Martinez L, Ferry JA, Peh SC: Extranodal NK/T-cell lymphoma, nasal type; in Jaffe ES, Harris NL, Stein H, Vardiman JW (eds): World Health Organization Classification of Tumours of Haematopoietic and Lymphoid Tissues. Lyon, IARC Press, 2008, pp 285-288.
6 Gollub MJ: Imaging of gastrointestinal lymphoma. Radiol Clin North Am 2008;46:287312.

7 Chen WL, Tsai WC, Chao TY, Sheu LF, Chou JM, Kao WY, Chen YC, Ho CL: The clinicopathological analysis of 303 cases with malignant lymphoma classified according to the World Health Organization classification system in a single institute of Taiwan. Ann Hematol 2010;89:553-562.

8 Yang QP, Zhang WY, Yu JB, Zhao S, Xu H, Wang WY, Bi CF, Zuo Z, Wang XQ, Huang J, Dai L, Liu WP: Subtype distribution of lymphomas in Southwest China: analysis of 6,382 cases using WHO classification in a single institution. Diagn Pathol 2011;6:77. 
9 Aoki R, Karube K, Sugita Y, Nomura Y, Shimizu K, Kimura Y, Hashikawa K, Suefuji N, Kikuchi M, Ohshima K: Distribution of malignant lymphoma in Japan: analysis of 2260 cases, 2001-2006. Pathol Int 2008;58:174182.

10 Chbani L, Hafid I, Berraho M, Nejjari C, Amarti A: Digestive cancers in Morocco: FezBoulemane region. Pan Afr Med J 2012;13:46.

11 Ghai S, Pattison J, Ghai S, O'Malley ME, Khalili K, Stephens M: Primary gastrointestinal lymphoma: spectrum of imaging findings with pathologic correlation. Radiographics 2007;27:1371-1388.

12 Nakamura S, Matsumoto T, Iida M, Yao T, Tsuneyoshi M: Primary gastrointestinal lymphoma in Japan: a clinicopathologic analysis of 455 patients with special reference to its time trends. Cancer 2003;97: 2462-2473.

13 Gurney KA, Cartwright RA, Gilman EA: Descriptive epidemiology of gastrointestinal non-Hodgkin's lymphoma in a populationbased registry. Br J Cancer 1999;79:19291934.

14 Papaxoinis G, Papageorgiou S, Rontogianni D, Kaloutsi V, Fountzilas G, Pavlidis N, Dimopoulos M, Tsatalas C, Xiros N, Economopoulos T: Primary gastrointestinal nonHodgkin's lymphoma: a clinicopathologic study of 128 cases in Greece. A Hellenic Cooperative Oncology Group study (HeCOG). Leuk Lymphoma 2006;47:2140-2146.

15 Lewin KJ, Ranchod M, Dorfman RF: Lymphomas of the gastrointestinal tract: a study of 117 cases presenting with gastrointestinal disease. Cancer 1978;42:693-707.

16 Li M, Zhang S, Gu F, Xiao W, Yao J, Chao K, Chen M, Li J, Zhong B: Clinicopathological characteristics and prognostic factors of primary gastrointestinal lymphoma: a 22-year experience from South China. Int J Clin Exp Pathol 2014;7:2718-2728.

17 Ding D, Pei W, Chen W, Zuo Y, Ren S: Analysis of clinical characteristics, diagnosis, treatment and prognosis of 46 patients with primary gastrointestinal non-hodgkin lymphoma. Mol Clin Oncol 2014;2:259-264.
18 Arora N, Manipadam MT, Pulimood A, Ramakrishna BS, Chacko A, Kurian SS, Nair S: Gastrointestinal lymphomas: pattern of distribution and histological subtypes: 10 years experience in a tertiary centre in South India. Indian J Pathol Microbiol 2011;54:712-719.

19 Warrick J, Luo J, Robirds D, Branson J, Frater JL, Kreisel F, Hassan A, Nguyen TT: Gastrointestinal lymphomas in a North American population: clinicopathologic features from one major Central-Midwestern United States tertiary care medical center. Diagn Pathol 2012;7:76.

20 Ghimire P, Wu GY, Zhu L: Primary gastrointestinal lymphoma. World J Gastroenterol 2011;17:697-707.

21 Hans CP, Weisenburger DD, Greiner TC, Gascoyne RD, Delabie J, Ott G, Muller-Hermelink HK, Campo E, Braziel RM, Jaffe ES, Pan Z, Farinha P, Smith LM, Falini B, Banham AH, Rosenwald A, Staudt LM, Connors JM, Armitage JO, Chan WC: Confirmation of the molecular classification of diffuse large Bcell lymphoma by immunohistochemistry using a tissue microarray. Blood 2004;103. 275-282.

22 Zhang Z, Shen Y, Shen D, Ni X: Immunophenotype classification and therapeutic outcomes of Chinese primary gastrointestinal diffuse large B-cell lymphoma. BMC Gastroenterol 2012;12:77.

23 Huang J, Jiang W, Xu R, Huang H, Lv Y, Xia Z, Sun X, Guan Z, Lin T, Li Z: Primary gastric non-Hodgkin's lymphoma in Chinese patients: clinical characteristics and prognostic factors. BMC Cancer 2010;10:358.

24 Kim SJ, Choi CW, Mun YC, Oh SY, Kang HJ, Lee SI, Won JH, Kim MK, Kwon JH, Kim JS, Kwak JY, Kwon JM, Hwang IG, Kim HJ, Lee JH, Oh S, Park KW, Suh C, Kim WS: Multicenter retrospective analysis of 581 patients with primary intestinal non-Hodgkin lymphoma from the Consortium for Improving Survival of Lymphoma (CISL). BMC Cancer 2011;11:321.

25 Wu X, Li P, Zhao J, Yang X, Wang F, Yang YQ, Fang F, Xu Y, Zhang H, Wang WY, Yi C: A clinical study of 115 patients with extrano- dal natural killer/T-cell lymphoma, nasal type. Clin Oncol 2008;20:619-625.

26 Gualco G, Domeny-Duarte P, Chioato L, Barber G, Natkunam Y, Bacchi CE: Clinicopathologic and molecular features of 122 Brazilian cases of nodal and extranodal NK/T-cell lymphoma, nasal type, with EBV subtyping analysis. Am J Surg Pathol 2011;35:1195-1203.

27 Pongpruttipan T, Sukpanichnant S, Assanasen T, Wannakrairot P, Boonsakan P, Kanoksil W, Kayasut K, Mitarnun W, Khuhapinant A, Bunworasate U, Puavilai T, Bedavanija A, Garcia-Herrera A, Campo E, Cook JR, Choi J, Swerdlow SH: Extranodal NK/T-cell lymphoma, nasal type, includes cases of natural killer cell and $\alpha \beta, \gamma \delta$, and $\alpha \beta / \gamma \delta$ T-cell origin: a comprehensive clinicopathologic and phenotypic study. Am J Surg Pathol 2012;36:481499.

28 Li S, Feng X, Li T, Zhang S, Zuo Z, Lin P, Konoplev S, Bueso-Ramos CE, Vega F, Medeiros LJ, Yin CC: Extranodal NK/T-cell lymphoma, nasal type: a report of 73 cases at MD Anderson Cancer Center. Am J Surg Pathol 2013;37: 14-23.

29 Kanemitsu N, Isobe Y, Masuda A, Momose S, Higashi M, Tamaru J, Sugimoto K, Komatsu $\mathrm{N}$ : Expression of Epstein-Barr virus-encoded proteins in extranodal NK/T-cell lymphoma, nasal type (ENKL): differences in biologic and clinical behaviors of LMP1-positive and -negative ENKL. Clin Cancer Res 2012;18:21642172.

30 Ying ZT, Zheng W, Wang XP, Xie Y, Tu MF, Lin NJ, Ping LY, Liu WP, Deng LJ, Zhang C, Zhu J, Song YQ: The clinical features, therapeutic responses, and prognosis of the patients with mantle cell lymphoma. Chin J Cancer 2012;31:348-353.

31 Kim SJ, Jung HA, Chuang SS, Hong H, Guo CC, Cao J, Hong XN, Suzuki R, Kang HJ, Won JH, Chng WJ, Kwong YL, Suh C, Song YQ, Zhu J, Tay K, Lim ST, Suzumiya J, Lin TY, Kim WS: Extranodal natural killer/T-cell lymphoma involving the gastrointestinal tract: analysis of clinical features and outcomes from the Asia Lymphoma Study Group. J Hematol Oncol 2013;6:86. 